\title{
Management of breast cancer: from standardization to personalization
}

\author{
Hideo Inaji
}

Published online: 4 September 2009

(C) The Japanese Breast Cancer Society 2009

It was an honor and a privilege to serve as President of the 16th Annual Meeting of the Japanese Breast Cancer Society (JBCS), held on 26-27 September 2008 in Osaka. First, I would like to express my sincere appreciation to all the participants and all the members of the organizing committee whose dedication made this event such a success.

The main theme of the meeting was "Management of breast cancer: from standardization to personalization," which emphasizes a focused effort at achieving the optimal and most efficient management of the breast cancer patient. Needless to say, it is quite important to standardize the management of breast cancer as one of the major milestones on the road to evidence-based medicine (EBM). However, at this point, with that objective having been attained to a certain extent, I am convinced that management of breast cancer should be directed towards personalization. Lately, we frequently encounter terms such as "personalization" or "individualization" as themes of various meetings relating to cancer. For example, the keynote theme of the 2009 Annual Meeting of the American Society of Clinical Oncology (ASCO) is "Personalizing Cancer Care" [1]. Let me cite the message from Dr. Richard L. Schilsky, 2008-2009 ASCO President: "Each patient with cancer is different-biologically, clinically,

The author was the president of the 16th Annual Meeting of the Japanese Breast Cancer Society.

\section{H. Inaji $(\bowtie)$}

Department of Breast and Endocrine Surgery,

Osaka Medical Center for Cancer and Cardiovascular Diseases,

1-3-3 Nakamichi, Higashinari-ku, Osaka 537-8511, Japan

e-mail: inaji-hi@mc.pref.osaka.jp economically, psychologically, and socially-and a onesize-fits-all approach to treatment, prevention, and survivorship is no longer appropriate" [1]. This especially holds true for the management of breast cancer. Therefore, the main theme of the 16th Annual Meeting of JBCS would appear to be very timely.

The total number of papers exceeded 1,500, and the meeting attracted more than 4,800 participants. Thus, the 16th meeting was a successful event in both scale and quality. It should also be noted that the meeting was held in conjunction with the 26th Congress of the International Association for Breast Cancer Research (IABCR). The latter congress, presided over by Prof. Sonoo of Kawasaki Medical School, was held on 22-24 September 2008 in Kurashiki. As a result, we had the good fortune to have a number of internationally prominent invited speakers from overseas. Indeed, the last week of September 2008 ultimately became "Breast Cancer Week" across a broad spectrum of breast oncology for the members of JBCS. My President's Address to the 16th Annual Meeting of JBCS, which has been published elsewhere in article form [2], incorporates some personal perspectives on my clinical research and explains why I chose this title as the main theme for the meeting. The abstracts of the 26th Congress of the IABCR have previously been published in this journal [3].

In this issue of Breast Cancer, several articles from the 16th Annual Meeting of the JBCS are presented as a presidential symposium entitled "Management of breast cancer: from standardization to personalization," together with a symposium entitled "Triple Negative Breast Cancer: Basics and Clinical Features." I would like to express my sincere thanks to the contributors. I refrain from referring in detail to these articles because they have been outlined by the chairpersons of each special session. 
It is my hope that implementation of the theme of the 16th Annual Meeting of the JBCS, "Management of breast cancer: from standardization to personalization," will be accelerated as a result of the invaluable presentations contained in these articles.

Acknowledgment I would like to conclude by extending my sincere thanks to all those who have devoted their time and energy to the organization of and preparation for this meeting.

\section{References}

1. http://www.asco.org/annualmeeting.

2. Inaji $\mathrm{H}$. Management of breast cancer-from standard to tailored. Jpn J Breast Cancer. 2009;24:173-80 (in Japanese with English abstract)

3. The Japanese Breast Cancer Society: Breast Cancer 15 (Supplement 1) 2008. 